\title{
A trajetória da família do portador de sofrimento psíquico
}

\author{
THE PATH OF THE PERSON'S FAMILY IN PSYCHIC SUFFERING \\ LATRAYECTORIA DAFAMILIA DEL PORTADOR DE SUFRIMIENTO PSÍQUICO
}

\author{
Vânia Morenoํ, Márcia Bucchi Alencastre²
}

\begin{abstract}
RESUMO
Este artigo é uma reflexão teórica acerca de como os familiares estiveram incluidos na assistência ao portador de sofrimento psíquico. Iniciamos a partir da constituição da psiquiatria enquanto ciência médica e buscamos chegar até os nossos dias. Percebemos que a família foi excluida do cuidado ao doente mental e que só veio receber a atenção e ser investigada a partir da Segunda Guerra Mundial quando começou o processo de desospitalização. No Brasil as estratégias visando auxiliar a família no enfrentamento do sofrimento psíquico ainda se encontram incipientes.
\end{abstract}

\section{PALAVRAS-CHAVE}

Família. Transtornos mentais. Psiquiatria/História.

\author{
ABSTRACT \\ This article is a theoretical \\ thought concerning how \\ relatives were included in the \\ attendance the person in \\ mental suffering. The onset \\ was the constitution of \\ Psychiatry as a medical \\ science up to our days. We \\ noticed that the family was \\ excluded from the care to the \\ mental patient and that \\ attention and investigation of \\ the matter only started after \\ World War II along with the \\ psychiatric outpatient \\ treatment process. In Brazil, a \\ strategy seeking to support \\ families facing psychic \\ suffering is still incipient.
}

\section{KEYWORDS}

Family. Mental disorders. Psychiatric/History.

\section{RESUMEN}

Este artículo es una reflexión teórica a cerca de cómo los familiares estuvieron incluidos en la asistencia a personas en sufrimiento psíquico. Iniciamos a partir de la constitución de la psiquiatría mientras ciencia médica y buscamos llegar hasta nuestros dias. Nos percatamos que la familia que excluida del cuidado al enfermo mental y que sólo vino a recibir la atención y ser investigada a partir de la Segunda Guerra Mundial cuando empezó. Actualmente algunos países han ofrecido asistencia al núcleo familiar y, cuando ocurre rechazo, la opción es por mantener contactos esporádicos del paciente con las familias de manera de evitar reinternaciones. En Brasil las estrategias visando a auxiliar la familia en el enfrentamiento del sufrimiento psíquico aún se encuentra incipiente.

PALABRAS-CLAVE

Familia. Trastornos mentales; Psiquiatría/Historia.
1 Enfermeira. Professora Assistente Doutor do Departamento de Enfermagem da Faculdade de Medicina de Botucatu Universidade Estadual Paulista. vmoreno@ fmb.unesp.br 2 Enfermeira.

Professora Doutora do Departamento de Enfermagem Psiquiátrica e Ciências Humanas da Escola de Enfermagem de Ribeirão Preto da Universidade de São Paulo. 


\section{INTRODUÇÃO E OBJETIVO}

A família tem ocupado um espaço privilegiado nas discussões sobre as políticas públicas sendo convidada a tornar-se aliada na formulação de um novo modelo de atenção à saúde. No cenário da saúde mental os familiares têm sido chamados a participar ativamente na implantação do projeto terapêutico do portador de sofrimento psíquico bem como são atores privilegiados na luta por melhores condições de assistência psiquiátrica.

Este estudo visa reconstruir a trajetória da família do portador de sofrimento psíquico desde a constituição da psiquiatria enquanto ciência médica no século XVIII até os dias atuais, enfocando períodos em que ocorrem mudanças na forma de inserção dos familiares nas formas de atendimento.

\section{A família: o "olhar" do primeiro reformador}

É preciso retornar no tempo para buscar como a família foi vista nos primórdios da psiquiatria.

Philippe Pinel, psiquiatra, considerado o primeiro reformador da assistência psiquiátrica, considerava relevante o transtorno mental ser decorrente de uma lesão no cérebro (causa física da doença mental), porém apontava outras três causas para a alienação mental, quais sejam: hereditariedade, influência de uma educação corrompida sobre a perda da razão e desregramento no modo de viver $^{(1)}$.

Essas foram denominadas por Pinel como "causas morais" e eram fatores predisponentes para o adoecer. O tratamento proposto era o moral que tinha como finalidade à substituição do ambiente onde residia o paciente de forma a curá-1o ${ }^{(2)}$.

Pode-se assinalar, também, que Pinel valorizou os fatores psicológicos do adoecer psíquico e, conseqüentemente, a família podia ser responsabilizada como causadora de doença, na medida em que não tinha controle sobre a educação falha e as paixões insuportáveis que acometiam os pacientes no ambiente familiar.

A primeira reforma na assistência psiquiátrica foi resultante do ideário da Revolução Francesa onde a família também passou por transformações, sendo proposto o modelo nuclear, composto de pai, mãe e filhos, correspondendo aos ideais da burguesia. O Estado teria controle sobre o planejamento das famílias de forma a assegurar as riquezas e obedecendo à racionalidade puramente econômica ${ }^{(3)}$.

Porém, no caso do doente mental, este ficaria aos cuidados do asilo, buscando-se reproduzir em um espaço fictício o modelo de família, onde o tratamento era fundamentado na "reeducação" moral e em normas de "bons costumes" $"(1)$.

Assim, a família foi banida do acompanhamento ao doente mental, cabendo apenas ao asilo e ao poder médico "curar" aqueles que apresentavam qualquer tipo de comportamento inadequado.

Cabe ressaltar que as determinações para os familiares ficarem longe dos pacientes durante o período de internamento tiveram impacto até 1980 , pois a família só podia visitar os mesmos quando a Instituição permitia e, normalmente, isso ocorria um mês após a internação ou quando já se encontravam melhor. A alegação era de que havia piora da sintomatologia quando o paciente entrava em contato com seu núcleo familiar e que eles, muitas vezes, não entendiam como o tratamento funcionava. Essa mesma norma valia para as correspondências, que deveriam ser avaliadas pelos profissionais, para não propiciarem reações negativas no doente; eram vetadas as cartas de pacientes que denunciavam as condições precárias de assistência.

Atualmente, o direito de visitas periódicas e de envio e recebimento de correspondência estão garantidos através da Declaração da Organização das Nações Unidas (ONU) sobre "A proteção de pessoas acometidas de transtorno mental e melhoria da assistência à saúde mental", de 1991.

\section{A familia: a partir da década de 40 atéo momento atual}

Enquanto a instituição psiquiátrica manteve-se como centro da assistência ao doente mental, a família teve uma pequena participação no cuidado ao seu paciente.

Os familiares de portadores de sofrimento psíquico só viriam a se tornar objeto de investigação no final da década de 40, situação esta decorrente "das críticas ao sistema asilar e paralelamente ao desenvolvimento de novas teorias acerca da doença mental "(4). 
As críticas ao modelo asilar iniciaram-se durante e após a Segunda Guerra Mundial, quando ocorreram novas reformulações da assistência psiquiátrica: Psiquiatria Institucional na França, Comunidade Terapêutica na Inglaterra, Psiquiatria Preventiva nos Estados Unidos e Psiquiatria Democrática na Itália. Todas estas formas propunham a transformação do espaço asilar e a possibilidade de desospitalização dos pacientes, ou seja, seu retorno à sua família e à sua comunidade.

Com a saída dos pacientes dos hospitais, novas teorias surgiram para buscar compreender a dificuldade de aceitação, pela família, do membro doente, principalmente em relação ao paciente com esquizofrenia.

As grandes teorias relacionadas às famílias de doentes mentais tiveram seu auge nos anos 50 e 60, pois os familiares passaram, então, a conviver mais de perto com o portador de sofrimento psíquico, situação que gerou muitas dificuldades de relacionamento e desencadeou, por vezes, reinternações ${ }^{(5)}$.

Os estudos buscavam entender o papel da família diante do adoecimento psíquico de um dos seus membros e os pressupostos teóricos dessas escolas constituíram a base da terapia familiar sistêmica, permitindo uma nova forma de visualizar a doença mental. Um diagnóstico que, anteriormente, era restrito ao paciente, passando a ser um sinal de dificuldades no núcleo familiar ao qual o paciente pertence. É, portanto, esta estrutura que deverá ser tratada e transformada ${ }^{(6)}$.

As famílias passaram a ser entendidas como sistemas que possuem um funcionamento e uma forma de comunicação que precisam ser modificados, pois causam sofrimento em um dos seus componentes. $\mathrm{O}$ paciente passou, então, a ser visto como depositário das dificuldades da dinâmica familiar.

A partir do embasamento da teoria sistêmica para compreensão da família, surgiram várias escolas de terapia familiar, sendo as principais: a estrutural, a estratégica breve e o grupo de Milão. Entre elas, existem muitas semelhanças, pois todas possuem o mesmo corpo teórico ${ }^{(7)}$.

Outra vertente, a psicanálise, também tem contribuído no tratamento das famílias, onde a ênfase não incide no alívio dos sintomas, mas na tentativa de vincular a interação atual dos membros da família a relacionamentos passados. O terapeuta, através da interpretação transferencial, mostra como relacionamentos reprimidos, oriundos da família de origem, se repetem nas famílias atuais ${ }^{(8-10)}$.

A abordagem psicodinâmica associa os princípios psicanalíticos aos conceitos sistêmicos. Essa técnica destina-se a penetrar nas defesas da família e propõe que o terapeuta tenha uma atitude aberta e pessoal, em contraposição ao papel do analista, reservado e afastado ${ }^{(11)}$.

As teorias sistêmica, psicanalítica e psicodinâmica têm contribuído para o entendimento dos núcleos familiares e representam recursos necessários para que os profissionais possam oferecer um melhor cuidado à família de portadores de sofrimento psíquico.

Uma crítica possível a ser feita é a de que essas teorias, ao realizarem a compreensão da questão familiar, acabaram também por classificar as famílias e rotulá-las como funcionais ou disfuncionais, estruturadas ou deses-truturadas ${ }^{(12)}$. Repetindo, assim, a trajetória do doente mental, por exemplo: um esquizofrênico vem de uma família disfuncional.

Na década de 60, iniciou-se uma série de estudos buscando entender as possíveis causas para as recaídas de pacientes esquizofrênicos, decorrentes do convívio familiar e social. Sendo elaborado um instrumento, a Entrevista Familiar de Camberwell para avaliar os aspectos do relacionamento entre o paciente e seus familiares ${ }^{(5)}$.

No decênio de 70, criaram o termo "Emoção Expressa" para designar um índice que avalia o número de comentários críticos, a presença de hostilidade e o nível de superenvolvimento do familiar com o paciente, que pode indicar características preditoras de recaída ${ }^{(13)}$.

Foi possível constatar que famílias com alto índice de "Emoção Expressa" têm dificuldade para tolerar os comportamentos e são mais críticas com o paciente, criando uma situação ambiental nociva, o que desencadearia um novo surto psicótico.

As investigações sobre "Emoção Expressa" permitiram o desenvolvimento de propostas terapêuticas visando modificar a interação familiar, de forma a melhorar a aceitação do paciente.
A trajetória da família

do portador de

sofrimento psíquico 
Vânia Moreno

Márcia Bucchi Alencastre
Uma das intervenções propostas a partir dos estudos sobre a "Emoção Expressa" é a abordagem psicoeducacional, que é educativa, não confrontacional e oferece suporte aos familiares, visando mudanças comportamentais.

Essa objetiva "mais que promover a ampliação do conhecimento de um paciente e sua família acerca do que é uma doença e seu tratamento". Busca ajudar o núcleo familiar na compreensão da experiência vivida e proporciona a incorporação desse entendimento em seu cotidiano como forma de valorizar a vida ${ }^{(14)}$.

A intervenção psicoeducacional tem sido utilizada para atender familiares de pacientes em sofrimento psíquico, de forma a garantir o convívio em comunidade, evitando recaídas e internações prolongadas ${ }^{(15-17)}$.

Quanto aos serviços de saúde mental, estes têm utilizado o processo de desinstitucionalização como forma de organização que busca criar uma relação mais solidária entre pacientes, equipe, família e comunidade.

Esse processo implica em colocar em discussão, os preconceitos travestidos de conhecimento científico e as práticas automatizadas, não para substituí-las definitivamente por outras afirmações supostamente corretas,

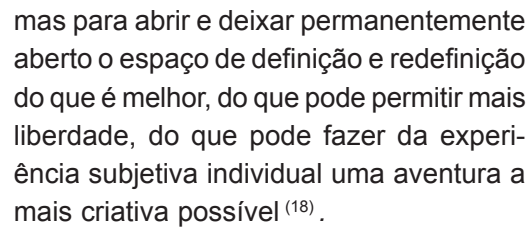

Diante disso, o trabalho de desinstitucionalização constitui-se um esforço permanente de desconstruir condutas tidas como únicas e verdadeiras e construir na multiplicidade de fatores que envolvem o relacionamento do portador de sofrimento psíquico e seus familiares uma experiência de convivência, a mais saudável possível.

Com relação às políticas públicas, um estudo ${ }^{(19)}$ sobre o processo de desinstitucionalização em vários países, ressalta a importância do estabelecimento de condições básicas de tratamento para o núcleo familiar. Pois, se a família não puder contar com uma rede de serviços que a auxilie no atendimento ao paciente, a tendência é repetir internações sucessivas. Os autores assinalam a existência de uma sobrecarga devido aos cuidados com a pessoa doente, prejudicando a interação familiar. Uma outra situação que pesa é o paciente tornar pública a doença mental na família, acarretando percalços para ambos no convívio com a comunidade.

É importante ressaltar que em alguns países, onde o processo de desinstitucionalização encontra-se consolidado, existem tratamentos diferenciados para pacientes que permaneceram longos anos internados em hospitais psiquiátricos ou aqueles em que o contato familiar é carregado de emotividade negativa e alto grau de críticas. O sistema de saúde optou pelo oferecimento de residências protegidas para esses pacientes e eles mantêm contatos esporádicos com as famílias, diminuindo assim a rejeição presente no ambiente familiar. Para que isso possa ser efetuado com sucesso, é necessária uma política de investimento que priorize a inserção social, na comunidade, do portador de sofrimento psíquico ${ }^{(20)}$.

\section{A familia: a assistência psiquiátrica no Brasil}

No Brasil, a organização da assistência psiquiátrica pautou-se no modelo da Escola Francesa e, também aqui, a família esteve banida de participar do tratamento do doente mental.

Os primeiros pacientes que foram internados no Hospício D. Pedro II eram aqueles destituídos de família: mendigos, alcoolistas, negros alforriados. Por outro lado, havia aqueles que sofriam de paixões, não aceitavam os princípios morais da sociedade e "deformavam a imagem da família". Também a estes cabia a internação psiquiátrica.

Durante a República, período da constituição do alienismo, as cidades se estabeleciam como um novo espaço de vida urbana e a polícia buscava manter a ordem. Os loucos eram aqueles que "sujavam as ruas". Para tanto, o local de reclusão era o hospício.

Havia, também, os loucos que pertenciam a famílias operárias, que diante da violência da polícia, optaram por delegar aos médicos o tratamento de seus enfermos, pois não tinham como cuidar dos mesmos devido à jornada de trabalho de doze horas diárias ${ }^{(21)}$.

E ainda, o poder médico utilizou a argumentação estratégica de que a loucura era de 
origem hereditária, para convencer as famílias da necessidade de exclusão de seus doentes.

Assim, satisfeita em esconder seus defeitos congênitos, a família cede o louco e perde a culpa de seu isolamento, que ainda acena com a perspectiva de cura(22).

O objetivo do alienista era de colocar-se como defensor e protetor da família buscando, através do tratamento, reorganizar o contato entre o doente e o núcleo familiar ${ }^{(23)}$.

Essa época deixou marcas profundas na assistência psiquiátrica, pois o número de pacientes crônicos e abandonados pela família representa um contingente enorme dos atuais moradores dos hospitais psiquiátricos.

Apenas com o movimento da Reforma Psiquiátrica, na década de 80 , que priorizou mudança do modelo assistencial, a família voltou a compor o cenário da assistência ao doente mental.

São marcos da Reforma Psiquiátrica as três Conferências Nacionais de Saúde Mental, realizadas respectivamente em 1987, 1992 e 2001 nas quais nos apoiaremos para fazer uma breve análise da inserção dos familiares no interior desse processo.

Na I Conferência Nacional de Saúde Mental, em 1987, as dificuldades enfrentadas pela família do paciente em sofrimento psíquico não obtiveram destaque. Cabe esclarecer que esta Conferência teve como objetivo consolidar as propostas do movimento da Reforma Sanitária no campo da Saúde Mental, objetivando o Sistema Único de Saúde. Foi uma Conferência que, quando da sua organização, procurou-se "dar ao evento um caráter congressual, isto é, de encontro científico de psiquiatras e profissionais de saúde mental "(24). As inquietações dos familiares e pacientes foram superficialmente contempladas em relação a como os serviços deveriam ser estruturados.

Decorridos cinco anos entre a primeira e a segunda Conferência, os familiares tiveram sua representatividade assegurada e uma das recomendações foi:

evitar culpabilizar o usuário e família, e promover o atendimento integrado da mesma inserida no contexto comunitário e social(25).
A terceira Conferência busca afirmar a importância da família como aliada na nova forma de atenção a ser ofertado ao portador de sofrimento psíquico onde se busca o suporte nos serviços através do cuidado domiciliar e enfrentamentos das crises. Enfatizam sua importância nos diversos momentos de negociação com os gestores na formulação de estratégias visando o melhor atendimento $^{(26)}$.

Outra questão muito enfatizada no Movimento da Reforma Psiquiátrica é a importância das mudanças culturais que devem ocorrer em relação ao imaginário social sobre a doença mental. O familiar é apontado como ator privilegiado nas transformações que deveriam acontecer no cuidado ao portador de sofrimento psíquico, centrado na acolhida, na escuta e em novas formas de convívio, através da superação dos tratamentos anteriores baseados no isolamento e exclusão ${ }^{(27)}$.

Os serviços precisam então elaborar programas visando atender as necessidades da família, quer em decorrência do primeiro episódio de sofrimento psíquico ou daqueles pacientes com várias internações, pois não se pode negar a sobrecarga que estas pessoas acarretam ao núcleo familiar.

O Ministério da Saúde, ao estabelecer as diretrizes da Saúde Mental pela Portaria 224, propõe o atendimento à família em todos os serviços, quais sejam: centros de atenção psicossocial, hospitais-dia, serviços de urgências psiquiátricas, unidades psiquiátricas em hospitais gerais e os hospitais especializados em psiquiatria, procurando assim incluir e ofertar ao núcleo familiar a possibilidade do cuidado em um período em que a família enfrenta uma crise.

Existe a necessidade da criação de um programa específico de preparação e incentivo (inclusive financeiro), para que as famílias acolham o paciente e também tenham uma rede de suporte nos serviços, como estratégias do processo de desinstitucionalização ${ }^{(28)}$.

O Ministério da Saúde propôs a criação de uma bolsa-auxílio de forma a garantir, através de suporte financeiro atrelado a programas terapêuticos, a manutenção do paciente no seu núcleo familiar e em sua comunidade ${ }^{(29)}$. Porém, esta proposta não foi viabilizada devido a questões jurídicas, pois o Estado não pode
A trajetória da família do portador de

sofrimento psíquico 
Vânia Moreno

Márcia Bucchi Alencastre ofertar dinheiro de forma direta aos beneficia$\mathrm{dos}^{(30)}$. Ainda assim, os recursos destinados a este projeto seriam menores do que aqueles gastos com internações hospitalares.

Desde o final da década de 70 e, mais constantemente, a partir da I Conferência de Saúde Mental, outros atores têm mostrado sua importância no campo das lutas por uma melhor assistência ao paciente com transtorno mental, como as associações de familiares e usuários. Essas associações têm produzido várias reflexões sobre a prática manicomial, inclusive defendendo os familiares que receberiam seus pacientes em casa, após longos períodos de internação, sem qualquer apoio.

Em uma investigação sobre as associações de usuários e familiares no Rio de Janeiro, é ressaltado que estas ocuparam espaços nos Conselhos Municipais de forma a legitimar e garantir que suas reivindicações sejam ouvidas.

Na verdade, o movimento que se faz não é de dar voz mas sim ouvir as vozes, pois elas sempre estiveram aonde estão, apenas os ouvidos não estavam na mesma freqüência. É uma questão de sintonia( ${ }^{(30)}$.

Com relação à Política Pública, cabe apontar que existe uma preocupação ao nível de Ministério da Saúde de prover os moradores das instituições psiquiátricas de forma a garantir sua reintegração social, sua reabilitação psicossocial e a humanização do atendimento através de Centros Residenciais Terapêuticos em Saúde Mental. No entanto esta estratégia será destinada "aqueles que já perderam o suporte social e laços familiares"(31).

Porém, por parte do Estado deveria haver uma perspectiva, a médio prazo, para aquela população que apesar de contar com laços familiares, esses ocorrerem de forma fragmentada, tênue acarretando ao portador de sofrimento psíquico várias internações sucessivas.

\section{CONSIDERAÇÕES FINAIS}

Este texto realizou uma reflexão teórica sobre a inserção da família na assistência ao portador de sofrimento psíquico. Em sua constituição a psiquiatria entendia que a família podia prejudicar o tratamento do doente men- tal, pois haveria necessidade de uma reeducação que seria fornecida pelos asilos. Isso acarretou sérios prejuízos levando ao afastamento dos familiares e pacientes, ocasionando um grande número de moradores em hospitais psiquiátricos.

Na década de 50 e 60, com a desospitalização ocorrendo em vários países, a família foi novamente chamada a compor o cenário da assistência, surgindo várias teorias para explicar e entender a doença mental. Uma das críticas possíveis à teoria sistêmica é que essa rotulou a família, repetindo um procedimento comum na psiquiatria enquanto ciência, ou seja, de classificar comportamentos e por conseqüência as pessoas.

No momento atual as Políticas Públicas dos diversos países em que vem avançando o processo de desospitalização, têm procurado garantir aos pacientes e seus familiares um convívio saudável. Em algumas famílias a convivência com o portador de sofrimento psíquico é tão difícil para ambas às partes que acarreta reinternações sucessivas para o paciente.

No Brasil não existe ainda um enfrentamento desta questão. Tem se buscado criar residências assistidas para aqueles destituídos dos laços familiares. Os pacientes com transtorno mental que possuem vínculo familiar, devem ser atendidos nos diversos serviços como os centros de atenção psicossocial, hospitais-dia, entre outros. E os familiares deverão receber um atendimento em momentos de crise e quando o paciente estiver inserido nos serviços.

Nessa direção, é importante ressaltar que temos que nos tornar aliados da família no processo de desinstitucionalização em curso. Conviver com os familiares ainda tem sido uma tarefa difícil a ser realizada pela equipe, que muitas vezes acaba por rotular as mesmas e responsabilizá-las pelo adoecimento mental de um de seus membros. Marcas que resistem ao tempo e à forma de cuidado ao portador de sofrimento psíquico. 
(1) Pessotti I. O século dos manicômios. São Paulo: Ed. 34; 1996.

(2) Bercherie P. Os fundamentos da clínica: história e estrutura do saber psiquiátrico. Rio de Janeiro: Zahar; 1989.

(3) Burguiere A. A formação do casal. In: Burguiere A, Klapisch-Zuber C, Segalen, M, Zonabend F. História da família: o choque das modernidades. Ásia, África, América, Europa. Lisboa: Terramar; 1998, p.98-125.

(4) Moreira LG. Família e doença mental: aspectos teóricos e práticos. [dissertação] São Paulo (SP): Faculdade de Medicina da USP; 1983.

(5) Menezes PR. Emoções expressas. In: Caetano D, Frota-Pessoa O, Bechelli LPC. Esquizofrenia: atualização em diagnóstico e tratamento. São Paulo: Atheneu;1981. p.83-8.

(6) Ponciano ELT. O indivíduo e família na terapia de família. In: Venâncio AL, Leal EM, Delgado PG. organizadores. O campo da atenção psicossocial. Rio De Janeiro: Te Cora-Instituto Franco Basaglia; 1997. p. 47-51.

(7) Calil VLL. Terapia familiar e de casal. São Paulo: Summus; 1987.

(8) Meyer L. Família e terapia. São Paulo: Brasiliense; 1981

(9) Berestein I. Família e doença mental. São Paulo: Escuta; 1988.

(10) Slipp S. Terapia familiar e terapia multi-familiar. In: Kaplan H, Sadock B. Compêndio de psicoterapia de grupo. Porto Alegre: Artes Médicas; 1996. p.226-36.

(11) Ackerman NW. Diagnóstico e tratamento das relações familiares. Porto Alegre: Artes Médicas; 1986.

(12) Villares CC, Mari JJ. Esquizofrenia e contexto familiar. In: Shirakawa I, Chaves AC, Mari JJ. Editors. O desafio da Esquizofrenia. São Paulo: Lemos Editorial; 1998. p. 243-55.

(13).Scazufca M. Avaliação de emoção expressa (EE) em familiares de pacientes psicóticos. Rev Psiquiatr Clín 1998; 25: 368-73.

(14) Andrade ACF. A abordagem psicoeducacional no tratamento do transtorno afetivo bipolar. Rev Psiquiatr Clin 1999; 26:1-8.
(15) Lagomarsino AL. Psicoeducación para familiares de esquizofrênicos. Acta Psiquiatr Psicol Am Lat. 1990; 36: 73-80.

(16) Zuñiga S, Jobet J. Psicoeducación y esquizofrenia: una experiencia en el servicio de psiquiatria del Hospital de Valdivia. Rev Psiquiatr1991; 8: 815-20, 1991.

(17) Zuñiga S, Jobet J. Evalución del programa de psicoeducación para familiares de pacientes esquizofrénicos: Una intervención complementaria al tratamento psicofarma-cológico y psicoterapéutico. Rev. Psiquiatr 1993; 10: 25-30.

(18) Bezerra Jr B. De médico, de louco e de todo mundo um pouco: o campo psiquiátrico no Brasil nos anos oitenta. In: Guimarães R, Tavares R, organizadores. Saúde e Sociedade no Brasil: anos 80. Rio de Janeiro: Relume Dumará, 1994. p.153-191.

(19) Morgado A, Lima LA Desinstitucionalização: suas bases e experiência internacional. J Bras Psiq, 1994; 43: 19-28.

(20) Bandeira M. Reinserção de doentes mentais na comunidade: fatores determinantes das re-hospitalizações. J Bras Psiq 1993; 9: 491-8

(21) Cunha MCP. Cidadelas da ordem: a doença mental na República. São Paulo: Brasiliense; 1990.

(22) Miranda CL. O nascimento da enfermagem psiquiátrica: o discurso moral e a sexualidade. Rio de Janeiro: UERJ/IMS, 1993.

(23) Machado R, Loureiro A, Luz R, Muricy K. Danação da norma: medicina social e constituição da psiquiatria no Brasil. Rio de Janeiro: Graal; 1978.

(24) Amarante P. Loucos pela vida: a trajetória da Reforma Psiquiátrica no Brasil. Rio de Janeiro: SDE/ENSP; 1995.

(25) Ministério da Saúde. Secretaria Nacional de Programas Especiais. Divisão de Saúde Mental. 2a . Conferência de Saúde Mental, 1992: relatório final. Brasília; 1994

(26) Ministério da Saúde. Conselho Nacional de Saúde. 3a . Conferência de Saúde Mental, 2001: relatório final. Brasília;2002.
A trajetória da família do portador de

sofrimento psíquico 
Vânia Moreno

Márcia Bucchi Alencastre
(27) Amarante P. Loucura, cultura e subjetividade: Conceitos e estratégias, percursos e atores da Reforma Psiquiátrica Brasileira. In: Fleury S, organizador. Saúde e democracia: a luta do CEBES. São Paulo: Lemos Editorial; 1997. p.163-85.

(28) Bandeira M. Desinstitucionalização ou transinstitucionalização: lições de alguns países. J Bras Psiq 1991; 7:355-360.

(29) Alves DSN. Por um programa brasileiro de apoio a desospitalização. Programa de apoio à desospitalização.(PAD) enquanto estratégia nacional de reabilitação. In: Pitta, AMF, org. Reabilitação Psicossocial no Brasil. São Paulo: Hucitec; 1996. p.27-30.
(30) Souza WS. Associações de usuários e familiares frente à implantação da política de saúde mental no município do Rio de Janeiro. [dissertação] Rio de Janeiro (RJ), Fundação Oswaldo Cruz, ENSP, 1999.

(31) Brasil. Portaria n.106, de 11 de fevereiro de 2000. In: Legislação em saúde mental. In: Ministério da Saúde.Legislação em saúde mental. Brasília; 2000. p. 85-89

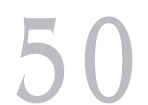

Rev Esc Enferm USP 2003; 37(2): 43-50 